\title{
The COVID-19 pandemic: A Comprehensive Review of the Genomic variations, Epidemiological features, Diagnosis, Treatment and Intervention schemes in South Asia
}

Abdullah Al Noman ${ }^{1}$, Jannatul Efte Ekra², Rima Islam Meem ${ }^{1}$, Md. Sujan Islam², Fariha Sharzana ${ }^{1}$, Md. Shofiqul Islam ${ }^{1}$, Samiron Sana ${ }^{3}$, Niaz Mahmud ${ }^{4}$, Md. Masnoon Kabir ${ }^{5}$, Abdullah Al Mahedi ${ }^{6}$, and Taufique Joarder ${ }^{7}$

${ }^{1}$ BioScience Academy Bangladesh, Dhaka, Bangladesh. Department of Genetic Engineering \& Biotechnology, Faculty of Biological Science and Technology, Jashore University of Science and Technology, Jashore-7408, Bangladesh ${ }^{2}$ BioScience Academy Bangladesh, Dhaka, Bangladesh. Department of Biochemistry and Molecular Biology, Faculty of Life Science, Mawlana Bhashani Science and Technology University, Tangail-1902, Bangladesh

${ }^{3}$ BioScience Academy Bangladesh, Dhaka, Bangladesh, Department of Pharmacy, Faculty of Biological Science and Technology, Jashore University of Science and Technology, Jashore-7408, Bangladesh. Pharmacy Discipline, Life Science School, Khulna University, Khulna-9208, Bangladesh

${ }^{4}$ Department of Nutrition and Food Technology, Jashore University of Science and Technology, Jashore-7408, Bangladesh

${ }^{5}$ International Centre for Diarrhoeal Disease Research, Bangladesh (ICCDR, B)

${ }^{6}$ Faculty of Medicine, Chittagong Institute of Medical Technology, Chattogram, Bangladesh

${ }^{7}$ Executive Director, Public Health Foundation, Bangladesh.

January 4, 2021

\begin{abstract}
The ongoing respiratory disease pandemic COVID-19 caused by a newly emerging highly infectious virus Severe Acute Respiratory Syndrome Coronavirus-2 (SARS-CoV-2) is aggravating the world's health, economy and regular life. This unprecedented respiratory outbreak has already infected more than 43 million individuals and taken more than 1.1 million lives. The habitation of over $21 \%$ of the world's population- the SAARC region is also susceptible to COVID-19 and comprises of more than $20 \%$ of the total infected cases. Demographic analysis showed that males and younger populations are mostly infected in South Asian countries. Similar genomic variations were observed in the countries such as variations in the ORF1ab, ORF1a, ORF3a and S genes were largely seen. As no effective treatment strategy hasn't developed yet, only timely testing and tracing can mitigate the loss from the disease which led the way to the development of alternate screening methods with higher efficiency and timely results. Since no unanimously recognized treatment option is available, existing medicines and treatments are being utilized to treat the patients. Currently, a vaccine can be the ideal solution for this rapidly evolving disease and hence two South Asian country- Bangladesh and India has joined the race of vaccine development and one of them succeeded the phase II clinical trial. As the 'Second Wave of COVID-19' is approaching, it has become a matter of urgency to appraise the existing policies and strategies in order to ascertain and implement effective schemes that can mitigate the ramifications of the disease.
\end{abstract}


Keywords: COVID-19 in South Asia; Genomic variations; Epidemiological Characteristics; Diagnostic system; Treatments contrivances; Interventions.

\section{Background}

The emergence of SARS-CoV-2 has been declared as a pandemic, which is an unprecedented outbreak of pneumonia that originated in China [1,2]. Bats were considered to be the host of this virus and $96 \%$ gene sequence homology was found between SARS-CoV-2 and a bat SARS-like-CoV whereas it only shares $79.6 \%$ similarity with SARS-CoV [3, 4]. Wild animals are regarded as the most potent natural reservoir of the coronavirus family. Two previous coronavirus epidemics- SARS and MERS were also transmitted by wild animals; from palm civets and dromedary camels, respectively [3]. On 31 December 2019, a cluster of pneumonia of unrevealed etiology was identified in Wuhan city of Hubei province in China [4]. Later, it was identified by the Chinese Center for Disease Control and Prevention (CDC) as a novel coronavirus [5]. The International Committee on Taxonomy of Viruses (ICTV) named it as Severe Acute Respiratory Syndrome Coronavirus 2 (SARS-CoV-2) because of its similarity with SARS-CoV and the World Health Organization (WHO) termed the disease as 'COVID-19' [6, 7]. The virus belongs to the family of coronaviridae and is an enveloped, single-stranded, positive-sense RNA virus [8]. It is the seventh of the already identified human coronaviruses including mild respiratory syndrome disease-causing coronaviruses HKU1, NL63, 229E, and OC43. SARS-CoV and MERS-CoV are the two other strains that have previously endangered human lives by causing two epidemics in China and the Middle East, respectively [8,9]. Phylogenetic analysis showed that SARS-CoV-2 was intimately connected to two bat-derived SARS-like coronaviruses, bat-SL-CoVZC45 and bat-SL-CoVZXC21, but were relatively less similar to SARS-CoV. COVID-19 is affecting 216 countries and territories around the world regardless of age, gender or race. As of 26 October 2020, around 43,837,698 confirmed cases and 1,166,142 deaths have been reported with a fatality rate of $2.66 \%$. At the same time, $32,188,661$ patients have recovered from COVID-19. Around 10,482,895 patients were taking treatment and of them, only 79,053 (less than 1\%) were critical till 26 October 2020 [10]. The USA is the most affected country to date with more than 8.9 million confirmed COVID-19 cases constituting more than $20 \%$ of the total infected patients and had 231,486 deaths up to 26 October 2020. On 30 January 2020, WHO has announced the disease as a public health emergency of international concern [11]. The South Asian countries have also been devastated by this highly infectious disease with 8,856,017 infected cases and 133,969 deaths up to 26 October 2020. South Asia consists of Afghanistan, Bangladesh, Bhutan, India, Iran, Maldives, Nepal, Pakistan, and Sri Lanka. India is facing its severe ramifications being the second-most-infected country with more than 7.9 million infected patients and 119,014 COVID-19 related deaths [12]. This review aims to outline the genome variations, epidemiological characteristics, diagnostic approaches, and treatment and prevention tactics of COVID-19 in the South Asian countries.

\section{Main Text}

\section{Genomic variations}

Analysis based on accessible documented data of genetic variation of this virus suggests that like all RNA viruses, SARS-CoV-2 contains indistinguishable mutation frequency and potential mutant distributions. Among the identified variants, fewer variants can cause long-standing infections. As RNA viruses have high mutation rates, this virus is likely to develop mutations to invade the host defense mechanism. Among the South Asian countries, India has sequenced the maximum number of the SARS-CoV-2 genome (570) among South Asian countries, followed by Bangladesh (231), Pakistan (11), Sri Lanka (4) and Nepal (1) as of 15 October 2020 [13]. Afghanistan, Bhutan and Maldives have not reported any genome sequencing yet.

An investigation on genomes of 184 SARS-CoV-2 virus strains from Bangladesh showed that 634 mutations 
were located in the entire genome resulting in 274 substitutions (non-synonymous) of amino acid in 22 unrelated proteins. Amino acid substitutions were prevalent at 48 different positions of the papain-like protease (nsp3) and no mutation was detected in nsp7, nsp9, nsp10, and nsp11. Moreover, nine unique mutations were observed in comparison with the global strains in the spike proteins [14]. Another analysis of 207 genomes from different areas of the country showed that 2602 mutations were observed of which 1602 were missense mutations, 612 were synonymous, 36 were insertions and deletions, and 352 were various types. Phylogenetic analysis implicated that the virus originated from Europe and GR clade was most prevalent in this region. A significant finding in these SARS-CoV-2 genomes was 7 unique alterations of amino acid from various proteins [15].

Analysis of 566 complete or almost complete Indian SARS-CoV-2 genomes found 3384 unique mutation points of which 933, 2449 and 2 were substitutions, deletions and insertions, respectively. Besides, 64 single nucleotide polymorphisms (SNP) were found. Of them, $57 \mathrm{SNPs}$ were present in six coding regions and 7 SNPs were present in 5'-UTR and 3'-UTR [16]. One comparative study found that the Indian SARS-CoV-2 strain showed a distinctive mutation in the spike glycoprotein (A930V $(24351 \mathrm{C}>\mathrm{T})$ ) which was absent in further strains [17]. Additionally, another analysis showed the origin of Indian SARS-CoV-2 strains from Europe and South-East Asia followed by local transmission. All the analyzed genomes were divided into four major clades 19A, 19B, 20A and 20B along with the new Nextstrain clade nomenclature and a rare clade 19B was identified which has a low occurrence in India [18].

The SARS-CoV-2 genome strain from Nepalese isolates revealed that it was more than $99.99 \%$ identical to two previously sequenced SARS-CoV-2 genomes (MN988668 and NC_045512) from Wuhan, China with seven additional sequences. Besides, five mutations were also identified based on the reference sequence EPI_ISL_405839 [19].

Full and partial genome sequencing of eight Pakistani isolates revealed that SARS-CoV-2 strains circulating in Pakistan were GH, S, L and I clade strains which are clustered with strains from Saudi Arabia, India, USA, Australia and China. Of the eight strains, five were GH clade with mutations in S glycoprotein D614G, Ns3 gene Q57H, and RNA dependent RNA polymerase P4715L. Among others, three were L clade, two were $\mathrm{S}$ clade, and one strain was I clade. Additionally, Orf1ab variant L3606F was observed in one GH and one L strain which indicates further evolutionary transitions [20]. In another analysis of 4 whole genome sequences, 31 variants were identified including two causing alterations in ORF1ab gene, ORF1a and N genes with functional replication and translation. Mutations in N \& ORF1a proteins showed alterations at the amino acid level [21].

Genome analysis of four SARS-CoV-2 isolates from Sri Lanka showed that the strains were clustered with strains from mostly Europe. SNP analysis revealed that the genome sequence of the first isolates showed variation in 6 nucleotides (nt) positions compared to the reference genome. The other three sequences have differed in 6 nt positions, 5 nt positions, and $4 \mathrm{nt}$ positions, respectively. Amino acid variants were found in the ORF1ab protein, S protein, ORF3a gene, M gene, and N protein of four Sri Lankan whole-genome strains, while the rest of the amino acids in the genes were unaltered [22].

\section{Epidemiological Characteristics}

Among the affected South Asian countries, India continues to be the most infected country. Almost $90 \%$ of the infected individuals in the South Asian region are from India, followed by Bangladesh, Pakistan and Afghanistan. In terms of COVID-19 deaths, Pakistan was in $2^{\text {nd }}$ position after India and followed by Bangladesh. Afghanistan had the highest mortality rate (3.70\%), followed by Pakistan $(2.05 \%)$ and India $(1.50 \%)$ as of 26 October (Table 1). Bhutan had the lowest number of infected patients; 342 individuals were infected while no one died. Around the same time, 7,923,759 (90\%) patients of the South Asian nations have been cured of the disease [12]. 


\section{Table1: Case distribution of COVID-19 in South Asian countries}

\begin{tabular}{lllll}
\hline Country & Total confirmed case & Total deaths & Mortality rate $(\%)$ & Total recovered \\
Afghanistan & 40,833 & 1,514 & 3.70 & 34,129 \\
Bangladesh & 398,815 & 5,803 & 1.45 & 315,023 \\
Bhutan & 342 & 0 & 0 & 307 \\
India & $7,909,959$ & 119,014 & 1.50 & $7,137,228$ \\
Maldives & 11,505 & 37 & 0.32 & 10,524 \\
Nepal & 158,089 & 847 & 0.53 & 111,670 \\
Pakistan & 328,602 & 6,739 & 2.05 & 311,075 \\
Sri Lanka & 7,872 & 15 & 0.19 & 3,803 \\
\hline
\end{tabular}

Due to the rapid spread and infection of a large population, it is difficult to maintain the complete databases of every individual. Hence, there is a lack of information in the demographic data. Existing demographic data analysis shows that there are variations in the age distribution of COVID-19 infected cases in South Asian countries. Most of the patients, infected with SARS-CoV-2 are young adults aged between 21-30 years except for Pakistan where people aged between 31-40 years are the most vulnerable and in Sri Lanka where the majority of the patients are aged between 41-50 years (Figure 1) [23-29].

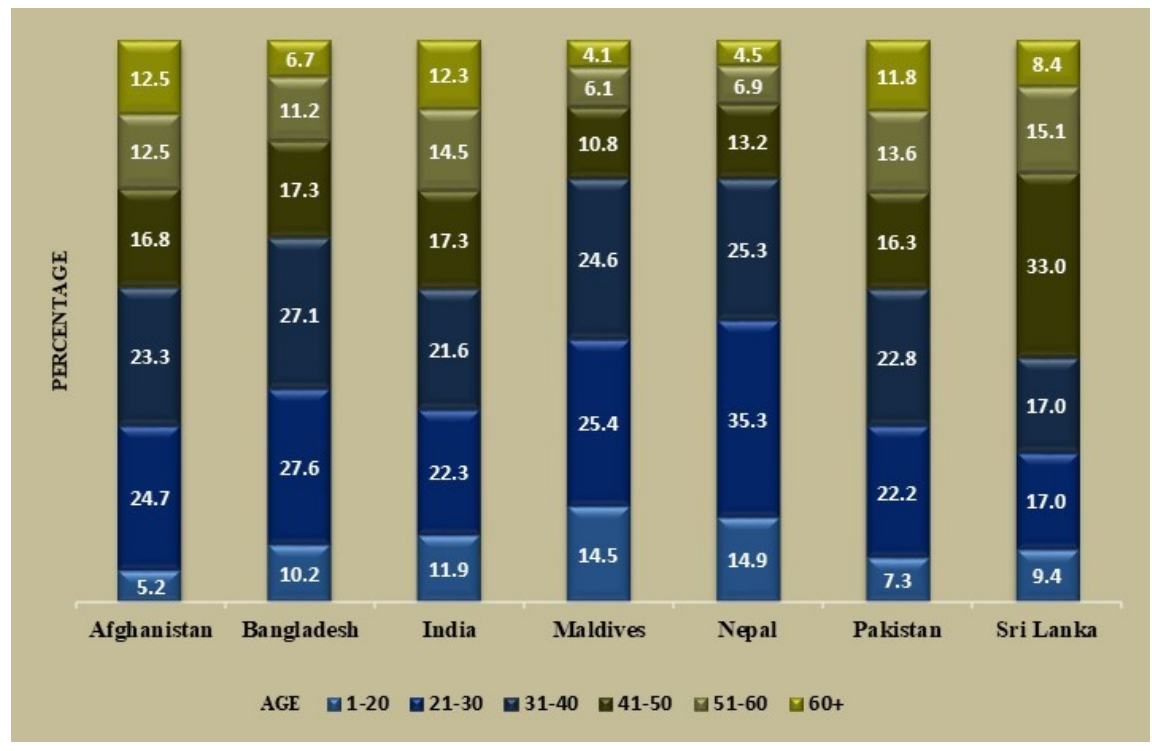

Figure 1: Age distribution of COVID-19 infected patients in South Asian countries [1].

[1] [Demographics data was not available for Bhutan and unspecified cases are not indicated in Afghanistan (5\%), Maldives (14.5\%) and Pakistan-(6\%)]

Though there is no scientific evidence for young people being affected at a higher rate, it is easily predictable that they are more likely to avert the interventions such as the use of face masks in public spaces, social distancing and quarantining. Regarding gender distribution, males are more susceptible to SARS-CoV-2 than females as females are genetically and immunologically more resistant to SARS-CoV-2 infection [30] (Figure 2) [23-29]. 


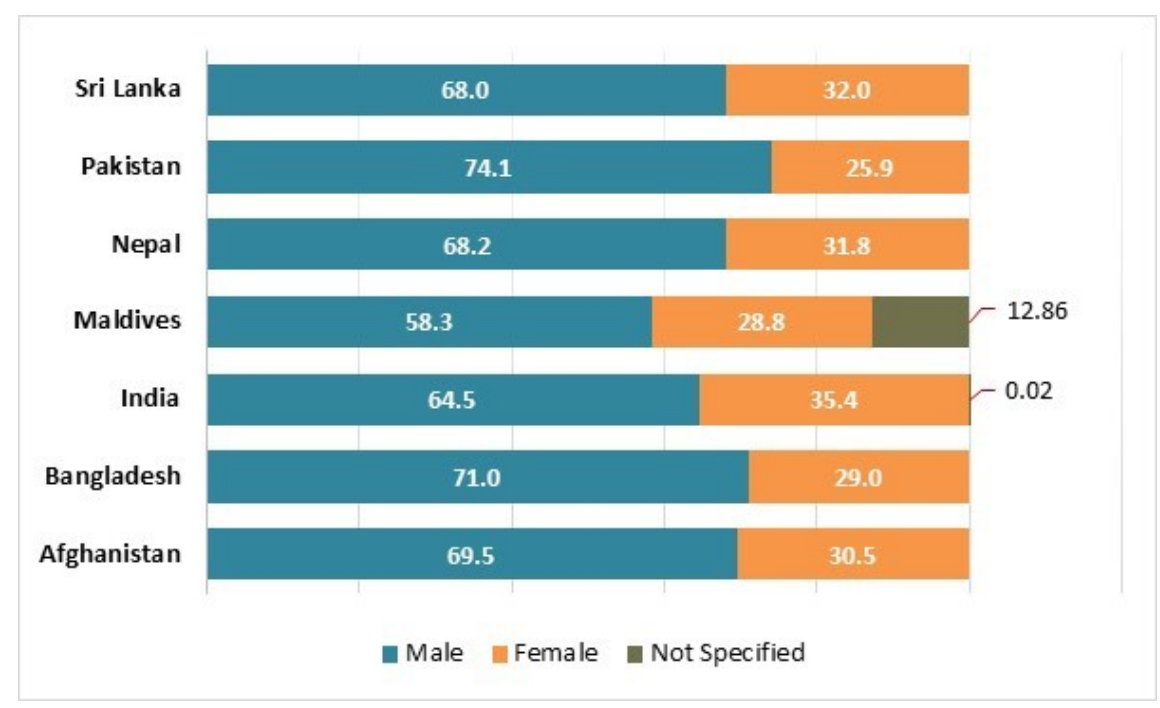

Figure 2: Sex distribution of COVID-19 infected patients in Soth Asian countries [2].

\section{[2] [ Demographics data was not available for Bhutan]}

It has been found that SARS-CoV-2 utilizes angiotensin-converting enzymes 2 (ACE-2) both as receptors and the route of infection. Analysis of the expression level and pattern of human ACE-2 using a single-cell RNAsequencing (RNA-seq) has revealed that Asian males have elevated expression of ACE 2 receptor than females and female ovaries have much lower levels of ACE-2 than male testes [31, 32]. Another reason is that the $\mathrm{X}$ chromosome possesses a significantly elevated amount of immune-related genes and regulatory elements. These genes and elements are directly involved in the modulation of the innate, as well as adaptive immune responses and hence, women have much immunologically stronger immunity against infectious diseases [33]. Several other social and cultural factors are deemed to be the reasons behind this. For example, smoking, tobacco use and alcohol consumption are more prevalent in men [34, 35]. Moreover, in the case of awareness and hygiene practices of the COVID-19, females act more responsibly and are reported to take necessary precautionary measures than men [36].

\section{Diagnostics Approaches}

Since the discovery of this ongoing COVID-19 pandemic, every country is trying to overcome it by following several courses of action. Among these, diagnostic measures have gotten prime concern as no reliable vaccines are available as yet.

Different methods are being used to find the presence of this fatal virus in people which are mainly categorized into molecular tests such as reverse transcriptase Real-Time Polymerase Chain Reaction (rRT-PCR) and serological tests such as rapid diagnostic test, Enzyme-Linked Immunosorbent Assay (ELISA), neutralization assay and chemiluminescent immunoassay [37]. The rRT-PCR of nasopharyngeal swabs has been regarded as the 'gold standard' testing method and various rRT-PCR based protocols have been uploaded to WHO technical guidance for laboratory testing of COVID-19 [38]. Though the detection of SARS-CoV-2 RNA is highly specific and less sensitive in some cases which can take a relatively long time and may produce false-negative results [39], still rRT-PCR assay is currently the most prevalent and accurate method to detect all types of coronaviruses including SARS-CoV-2 [40-42].

Among the South Asian countries, India has the highest number of testing facilities with 2134 SARS-CoV-2 detection labs including 1115 rRT PCR labs, 851 TrueNat test labs and 128 Cartridge-Based Nucleic Acid Amplification test (CBNAAT) labs [43]. In Afghanistan, there are only 14 COVID-19 designated labs, while 
there are 109 in Bangladesh, 6 in Bhutan, 9 in the Maldives, 76 in Nepal, 146 in Pakistan and 17 in Sri Lanka [44-51]. Table 2 lists different diagnostic methods approved and used in the South Asian countries.

Table-2: COVID-19 diagnostic methods in South Asian countries.

\begin{tabular}{|c|c|c|}
\hline Country name & Screening Method & Synopsis \\
\hline \multirow[t]{2}{*}{ Afghanistan } & rRT-PCR & Sample: Oropharyngeal and nasopharyngeal s \\
\hline & rRT-PCR & Sample: Nasopharyngeal swab, oropharyngeal \\
\hline \multirow[t]{3}{*}{ Bangladesh } & GeneXpert Covid-19 Test & Sample: Saliva. Result: within 45 mins. \\
\hline & Rapid Dot Blot & Sample: Blood Result: within 15 mins. Relia \\
\hline & rRT-PCR & Sample: Upper respiratory sample (nasal and \\
\hline \multirow[t]{4}{*}{ Bhutan } & Rapid Diagnostic Test & Sample: Blood Result: 30 mins Reliability: 90 \\
\hline & rRT- PCR & Sample: Nasal, oral and throat swab, sputum. \\
\hline & Feluda-CRISPR Test & Sample: Nasal or throat swab. Result: within \\
\hline & Rapid Antibody Test & Sample: Blood. Result: within 20-30mins. \\
\hline \multirow[t]{5}{*}{ India } & Rapid Antigen Test & Sample: Nasal swab. Result: within 30 mins. \\
\hline & TrueNat & Sample: Nasal swab, oral swab. Result: within \\
\hline & CBNAAT & Result: within 60 mins \\
\hline & ELISA based antibody test & Sample: Blood serum or plasma. Reliability: 9 \\
\hline & rRT-PCR & Sample: Combined oropharyngeal and nasop \\
\hline \multirow[t]{4}{*}{ Maldives } & GeneXpert Test & Sample: Swab sample. Result: Within $45 \mathrm{mil}$ \\
\hline & Rapid Antigen Test (BinaxNOW COVID-19 Ag Card) & Reliability: $97 \%$ sensitivity, $98.5 \%$ specificity. \\
\hline & Antibody Test & Reliability: $100 \%$ sensitivity, $99 \%$ specificity. \\
\hline & rRT-PCR & Sample: Nasal swab or throat swab. \\
\hline \multirow[t]{2}{*}{ Nepal } & Rapid Diagnostic test & Sample: Blood. Reliability: $50 \%$ sensitivity, 9 \\
\hline & rRT-PCR (N-CovKit) & Sample: Nasopharyngeal swab, oropharyngeal \\
\hline Pakistan & Rapid Digital Test & Sample: Blood Result: within minutes. Relial \\
\hline Sri Lanka & rRT-PCR & Sample: Nasopharyngeal swab, oropharyngeal \\
\hline
\end{tabular}

In terms of COVID-19 testing, most of the South Asian countries are far from reaching the target number required to test every confirmed case. Afghanistan is conducting only 2814 tests per million population, the lowest in South Asia, followed by Bangladesh (11567/1000000), Sri Lanka (13051/1000000) and Pakistan (15416/1000000) as of 26 September 2020 (Fig. 3) [68]. 


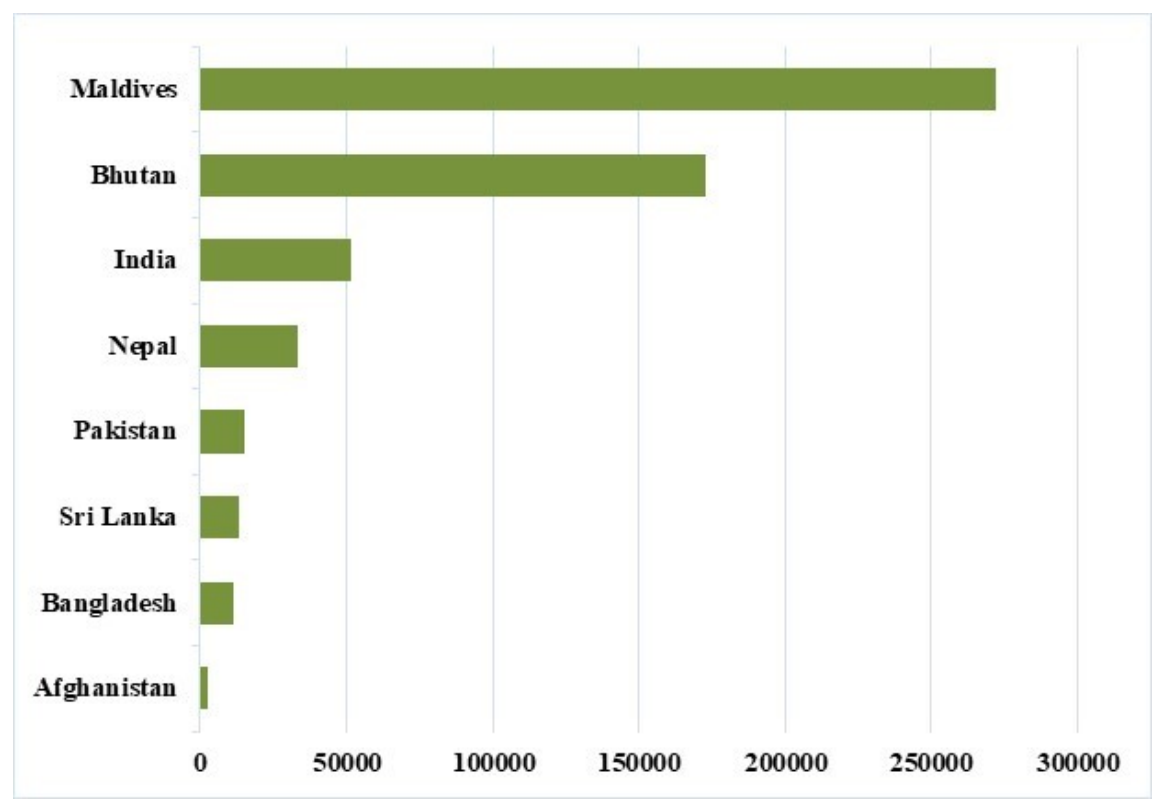

Figure 3: COVID-19 testing per million populations in South Asian countries.

\section{Treatment Strategies}

In Afghanistan, a controversial drug produced by a traditional healer has become the talk of the town, which was reported to be made up of addictive substances such as morphine and codeine. Although the government and health experts have warned against this unproven drug, general people have burst with excitement to take the medication [69]. Plasma therapy has also been found to be effective in the treatment of COVID-19 patients in Afghanistan which is currently the most promising treatment for the disease [70]. The country is one of the worst sufferers of COVID-19 as the treatment facilities are below standard and still cannot meet the requirement.

According to the "National Guidelines on Clinical Management of Coronavirus Disease-2019 Bangladesh," Chloroquine, Hydroxychloroquine and Azithromycin were prescribed to be used in the treatment of COVID19 patients [71]. A team of doctors from Bangladesh Medical College Hospital found that a combination of antiprotozoal medicine Ivermectin in a single dose with antibiotic Doxycycline can be effective to treat COVID-19 patients though more clinical trials are needed to be done to evaluate its efficacy [72]. A Bangladeshi pharmaceutical company, Beximco had launched the world's first generic Remdesivir and currently exporting Remdesivir IV injection "Bemsivir" [73]. Favipiravir - an antiviral drug that showed efficiency against influenza A and B has also been found promising to treat SARS-CoV-2 infection in patients [74]. CP therapy has been found effective in Bangladesh, especially in critical cases when plasma therapy is the only option [75].

Among the South Asian countries, Bhutan has got special praise from the WHO for conducting timely diagnosis and treatment to combat the deadly COVID-19 pandemic. Bhutan has provided free testing facilities which resulted in timely diagnosis and treatment. As per the National Clinical Management Guideline, patients having mild symptoms with risk factors to pneumonia and other symptoms are treated with Hydroxychloroquine with or without Lopinavir/Ritonavir [76]. Additional therapies such as low molecular weight heparin, steroids and antibacterial are included for case by case usage [77].

India, one of the most affected countries, is facing a critical phase and looking for effective treatment methods. Hydroxychloroquine is being recommended for mild cases whereas a combination of Hydroxychloroquine and Azithromycin for severe patients in India [78]. The central government has authorized two antiviral drugs 
- Remdesivir and Favipiravir, but a debate has always been remaining among the medical experts about the competency in treating COVID-19 patients [79]. Itolizumab, an anti-CD6 humanized monoclonal IgG1 antibody got approval for the treatment of moderate and severe patients [80]. Another hopeful treatment that has emerged is convalescent plasma (CP), or immune plasma therapy. The Indian Council of Medical Research (ICMR) had launched clinical trials to evaluate its safety and efficacy. This treatment may serve as a short-term solution to suppress mortality rates [81].

The Maldives has published COVID-19 Quick Reference Guidelines to provide information on clinical and home management. According to this, empirical antibiotics have been recommended based on clinical diagnosis along with Oseltamivir for mild and moderate patients [82]. As a consequence, the government has transported antiviral drugs such as lopinavir and ritonavir from India to ensure medications [83].

Most of the patients of Nepal are being treated with regular medications while Hydroxychloroquine, the controversial anti-malarial drug, was also being used in some cases. Health experts, however, emphasized that Hydroxychloroquine was not that efficient in treating COVID-19 and patients may face several sideeffects including loss of vision and heart ailments [84]. The Department of Drug Administration has signed a consignment deal with Indian company Mylan to import Remdesivir, an antiviral injection used to treat COVID-19 patients with critical symptoms [85]. Nepal's health authorities have declared that their first plasma therapy treatment has become successful [86].

In Pakistan, Dexamethasone is being used to treat critical COVID-19 in patients. The WHO has addressed it as a "lifesaving breakthrough" and stated that it had reduced mortality by about one-third for patients on ventilators, and by about one-fifth for patients requiring oxygen [87]. Health experts in Pakistan prescribed Hydroxychloroquine tablets which they found efficient and secured for the patient, ignoring the warnings of the WHO [88]. The Specialized Healthcare and Medical Education Department approved Actemra interleukin-6 inhibitor with the generic name of Tocilizumab - an immune-suppressant, for the critical SARS-CoV-2 affected patients on prescription only. However, the regional government is yet to formally approve the drug, recommended by the WHO [89]. Besides, Remdesivir is also being used for the treatment of COVID-19 patients [90]. Convalescent plasma which contains antibodies generated by the recovered patients is gaining popularity across Pakistan [91].

Sri Lankan Provisional Clinical Practice Guidelines on COVID-19 suspected and confirmed patients recommended antipyretics for mild patients [92]. Sri Lanka has been a country that promotes ayurvedic and herbal medicine to fight against COVID-19. Herbal therapy has been introduced under government supervision. An immunizing drink named "Suwadharani Immunizing Drink" and also a powder named "Sadanga Panaya" have been developed for the individuals infected with the SARS-CoV-2 virus [93, 94].

\section{Intervention schemes}

It is too tough to take essential steps for combating COVID-19 in war-torn Afghanistan. But still, the Afghan government is trying its utmost to take containment measures after the first case was identified. The measures include decreasing activity at borders entry, arranging quarantine facilities for infected people, and establishing strict restrictions on movement [95, 96]. They declared a countrywide lockdown on 28 March 2020. The authorities proposed a budget for COVID-19-related expenditure such as 6.2 billion Afghani (Af) for health packages, 23.6 billion Af for social packages including bread distribution program, and 1.7 billion Af for wheat purchase program [96]. The government received 300 million USD grants from the World Bank and another 400 million USD under the Incentive Program Development Policy Grant of the International Development Association (IDA) and Afghanistan Reconstruction Trust Fund to shore up the economy, provide aid to civil services and minimize the ramifications of COVID-19 in Afghanistan [97].

In Bangladesh, almost after two months of the Wuhan outbreak, on 8 March 2020, the first three cases were detected. To stop the spreading of pandemic throughout the country, the government declared general holidays and ordered a lockdown throughout the country on 23 March 2020 [98]. Finally, on 31 May 2020, the countrywide lockdown was withdrawn after extending several times, but the government split the country into three zones according to disease prevalence [99]. The government has made a rule for wearing a face mask 
and took several steps for public awareness and also opened a hotline and made sure about the quarantine of foreign returnees[100]. In addition to these, they declared 19 stimulus packages worth over 1.03 trillion USD to support various sectors for combating the COVID-19 [101]. Bangladesh is also competing in the race of vaccine development where one of the indigenous pharmaceutical companies named Globe Biotech has become successful in its two-phase animal trials in the pre-clinical stage. If they get ethical approval from the Bangladesh Medical Research Council (BMRC), then they will conduct human trials to examine whether the dose is safe and effective for humans [102].

The first COVID-19 case was identified on 6 March 2020 in Bhutan and the government immediately closed its border and educational institutes for 2 weeks and extended this closure several times [103]. They made it compulsory for foreign returnees to be quarantined [103]. The government built two mobile apps named "Stay Home App" and "Druk Trace App" for helping and providing accurate information about COVID-19 and for tracing people who come in direct contact with COVID-19 affected people [104, 105].

India declared 'Janata Curfew' on 22 March 2020, after confirming the first case and countrywide restriction on movement on 25 March 2020 [106]. India has launched a mobile app called 'Aarogya Setu' for raising awareness of the COVID-19 and a WhatsApp chatbot called 'My Gov Corona Helpdesk' for ensuring accurate information and to stop rumors [107]. The government took an initiative to set up 2 million retail shops called 'Suraksha Stores' to ensure everyday essentials to citizens by maintaining safety measures throughout India [108]. To prevent the massive SARS-CoV-2 infection, the Indian government suspended all visas and closed all educational institutes. The government has declared an incentive package of USD 280 Billion to decrease economic loss and keep a balance between health practices and the economy [109]. India-based companies named Zydus Cadila and Bharat Biotech, in partnership with ICMR, are leading the spurt of COVID-19 vaccine development in the country. Bharat Biotech's Covaxin has got approval to conduct the Phase III trials whereas, Zydus Cadila's COVID vaccine is undergoing the phase II trials after obtaining promising and positive results [110].

The Maldives detected its first case on 7 March 2020, and the government imposed a lockdown on 16 April $2020[111,112]$. In addition to this, they have turned an island into a quarantine facility called the world's first coronavirus resort [113]. The country has been divided into six zones so that each zone can be graded individually for engagement, preparedness and response. Moreover, the government developed a training plan for increasing professional skills among the health workers and introduced risk allowance for the civil servants who are working in the frontline in the COVID-19 response [114].

Nepal first confirmed its SARS-CoV-2 positive case on 23 January 2020 [115]. The Nepal government has taken several strategies to prevent transmission of the virus such as they suspended all international flights and formed a multi-agency coordination committee to stop the spread of COVID-19 [116]. They increased the number and facilities of self and institutional isolation and quarantine wards in hospitals of all the provinces [117]. Nepal also closed all educational institutions and declared a countrywide lockdown on 24 March 2020. All of their existing public health and community-based networks and other line ministries and development partner networks are coordinately working for ensuring public awareness and providing accurate information [118]. Nepal is also volunteering in the third-phase clinical trials of three COVID-19 vaccines conducted by three companies from China, Russia, and the UK. If they got approval from the Nepal Health Research Council, they will begin the trials soon [119].

The government of Pakistan has taken many effective steps after confirming the positive case. They formed a National Coordination Committee to s monitor COVID 19 situation regularly and took necessary steps such as closing all educational institutions along with the border and banning all public gatherings till 5 April 2020 [120]. Pakistan accepted 'Smart lockdown strategies' instead of blanket lockdown by recognizing 500 hotspots and imposed a lockdown on those areas [121]. The government has announced a stimulus package of 7.79 billion USD to assist businesses, emergency response, and to cover relief to residents [122]. Pakistan will also get the benefit of the vaccine trial from China. The phase 3 trial of the Chinese vaccine for COVID-19 will be held in Karachi's Indus Hospital [123]. 
A Chinese tourist was first detected as COVID-19 positive on 27 January 2020 in Sri Lanka and as a result, the government banned all international transports across the country. They banned all foreign travels and shut down all educational institutes [124]. To restrain and control the pandemic situation the government took some effective measures such as developing an active response mechanism team who are communicating directly with the root level people for growing awareness and for stopping the rumors [125].

\section{Discussion}

Genome analysis of SARS-CoV-2 suggests that this virus is rapidly evolving and numbers of distinct variants exist in most of the strains [126]. Simultaneously it is noticeable that most of the strains are still causing mutation and framing new emerging variations of those viral strains though there are common frequencies of mutation distributed in neighboring countries. Analysis of the sequenced genomes from the South Asian countries found that most of the strains adopted several mutations, mostly as insertions and/or deletions. Variations in the ORF1ab, ORF1a, ORF3a and S gene are most prevalent. Additionally, SNPs are significantly usual. Alterations in the levels of the amino acid markedly vary in the genome of SARS-CoV-2 isolates of these countries.

Though most of the infected patients of COVID-19 are younger adults, mortality rate is higher among the geriatric population [127] Similarly, it has been observed that males are more vulnerable to SARS-CoV-2 than females. So, males and young people who have to expose more to the outside due to work and other duties, need to be more aware of the hygiene practices. The use of face masks during traveling, maintaining social distance and continuous use of disinfectants to stay safe from the virus are some common health practices for COVID-19.

Every nation of South Asia is trying to expand its screening facilities by equipping more hospitals with rRT-PCR and other amenities. This early identification of SARS-CoV-2 infection may bring the COVID-19 pandemic under control by inhibiting the community transference. Although many months have passed, still there is no benchmark testing method like rRT-PCR in diagnosing COVID-19 infected patients. However, other COVID-19 confirmation methods like the Feluda test, TrueNat, CBNAAT, rapid antigen and antibody tests are also gaining popularity to soar up the number and availability of diagnostic tests. Apart from these, to reduce the cost of tests, Pakistan has invented their own kits for RT-PCR named N-CovKit. Over time, the massive spread and spontaneous mutation of SARS-CoV-2 have led the way of the development of new diagnosis methods having greater efficacy with quick result time such as Rapid Dot Blot in Bangladesh and Feluda paper strip test in India. Only proper testing, tracing and treatment can minimize the loss due to this virus but still, there is a lack of testing kits and diagnostic facilities in many South Asian Countries. Already vaccines of SARS-CoV-2 are under investigation in 198 countries of the world, and of them, 42 have been going under clinical trials [21]. Bangladesh (BANCOVID vaccine) and India (COVAX vaccine) are two South Asian countries competing and their vaccines are still undergoing clinical trials where they are working with various national and international collaborators to develop a promising vaccine soon. At this moment, an effective vaccine can be the best hope for all the countries.

Though no effective treatment has been discovered yet, all the South Asian countries are experimenting with the existing medicines and treatment strategies to strive against the pandemic. Specifically designed randomized clinical trials are urgently needed to determine the most appropriate evidence-based treatment. To stop the spread of COVID-19 and prevent the burden of any future outbreak, an effective modality of treatment is essential.

Almost every country has taken necessary actions to safeguard its people, but particularly Pakistan applied an innovative approach called 'Smart Lockdown' which helped stabilize their economy. India and Bhutan have developed several Apps for public awareness, while Bangladesh and Maldives have taken varied lockdown strategies according to disease prevalence to handle the pandemic situation properly. As all of the countries have been infected by either transborder movement or returnees from overseas, they need to be more careful 
about their borders and quarantine facilities and implement effective social containment strategies with a balance between economy and health practices.

\section{Conclusion}

The COVID-19 pandemic is a matter of global concern that has hampered every sector, from health to economy to society. No gender, nation and ethnic groups could evade the massive and rapid spreading of this highly infectious virus. Due to rapid and unpredictable transmission, classical health contrivances and surveillance measures are the only means to combat this pandemic. International and regional cooperations among the South Asian countries are mandatory to strive against the pandemic. Policymakers, government officials and experts of various fields from these countries should come forward to work hand in hand to establish response operations. Local and regional co-operative organizations have to work with the authorities of the countries to promote knowledge and awareness of the COVID-19 among their populations.

\section{Lists of Abbreviations}

COVID-19: Coronavirus Disease 2019; SARS-CoV-2: Severe Acute Respiratory Syndrome Coronavirus 2; SARS-CoV: Severe Acute Respiratory Syndrome Coronavirus; MERS-CoV: Middle East Respiratory Syndrome Coronavirus; WHO: World Health Organization; SNP: Single Nucleotide Polymorphism; ACE2: Angiotensin-Converting Enzyme 2; rRT-PCR: reverse transcriptase Real-Time Polymerase Chain Reaction; CBNAAT: Cartridge-Based Nucleic Acid Amplification Test; CT: Computed tomography; CDC: Centers for Disease Control and Prevention; DGDA: Directorate General of Drug Administration;

\section{CRediT authorship contribution statement}

AAN, JEE, RIM, MSI, FS, MShI- Conceptualization, Data curation, Formal analysis, Investigation, Methodology, Project administration, Software, Visualization, Writing - original draft, Writing - review \& editing.

SS, NM, MMK, AAM and TJ- Data curation, Formal analysis, Investigation, Methodology, Visualization, Writing - original draft, Writing - review \& editing.

\section{Availability of data and material}

All data and material are available upon request.

\section{Acknowledgment}

The authors are grateful to the Department of Genetic Engineering and Biotechnology, Jashore University of Science and Technology and Public Health Foundation of Bangladesh for providing their thoughts and guidance.

\section{Disclosure statement}

No potential conflict of interest was reported by the authors.

\section{Funding}

This research did not receive any grant from funding agencies in the public, commercial, or not-for-profit sectors.

\section{References}

1. Ge H, Wang X, Yuan X, Xiao G, Wang C, Deng T, et al. The epidemiology and clinical information about COVID-19. European Journal of Clinical Microbiology and Infectious Diseases. 2020;39:1011-9. doi:10.1007/s10096-020-03874-z. 
2. Zhou P, Yang X Lou, Wang XG, Hu B, Zhang L, Zhang W, et al. A pneumonia outbreak associated with a new coronavirus of probable bat origin. Nature. 2020;579:270-3.

3. Lu R, Zhao X, Li J, Niu P, Yang B, Wu H, et al. Genomic characterisation and epidemiology of 2019 novel coronavirus: implications for virus origins and receptor binding. Lancet. 2020;395:565-74.

4. Wang D, Hu B, Hu C, Zhu F, Liu X, Zhang J, et al. Clinical Characteristics of 138 Hospitalized Patients with 2019 Novel Coronavirus-Infected Pneumonia in Wuhan, China. JAMA - J Am Med Assoc. 2020;323:1061-9.

5. Chen N, Zhou M, Dong X, Qu J, Gong F, Han Y, et al. Epidemiological and clinical characteristics of 99 cases of 2019 novel coronavirus pneumonia in Wuhan, China: a descriptive study. Lancet. 2020;395:507-13.

6. Wang L, Wang Y, Ye D, Liu Q. Review of the 2019 novel coronavirus (SARS-CoV-2) based on current evidence. Int J Antimicrob Agents. 2020;55:105948.

7. International Committee on Taxonomy of Viruses (ICTV). 2017. https://talk.ictvonline.org/. Accessed 4 Sep 2020.

8. Chen Y, Liu Q, Guo D. Emerging coronaviruses: Genome structure, replication, and pathogenesis. Journal of Medical Virology. 2020;92:418-23.

9. Wu A, Peng Y, Huang B, Ding X, Wang X, Niu P, et al. Genome Composition and Divergence of the Novel Coronavirus (2019-nCoV) Originating in China. Cell Host Microbe. 2020;27:325-8.

10. Worldometer. Coronavirus Update - Worldometer. Worldometer. 2020. https://www.worldometers.info/coronavirus/. Accessed 26 Oct 2020.

11. Whitworth J. COVID-19: A fast evolving pandemic. Transactions of the Royal Society of Tropical Medicine and Hygiene. 2020;114:227-8.

12. Situation Report - SAARC Region | COVID-19 | SAARC Disaster Management Centre (IU). http://www.covid19-sdmc.org/situation-report. Accessed 26 Oct 2020.

13. NCBI Virus. $\quad$ https://www.ncbi.nlm.nih.gov/labs/virus/vssi/\#/virus?SeqType_$\mathrm{s}=$ Nucleotide\&VirusLineage_ss=Severe acute respiratory syndrome-related coronavirus, taxid:694009. Accessed 16 Oct 2020.

14. Sayeed Mohmmad Mahmud A, Taznin T, Murshed Hasan Sarkar M, Samir Uzzaman M, Osman E, Ahasan Habib M, et al. The genetic variant analyses of SARS-CoV-2 strains; circulating in Bangladesh. bioRxiv. 2020;:2020.07.29.226555.

15. Mahbub Hasan M, Das R, Rasheduzzaman M, Hamed Hussain M, Hasan Muzahid N, Salauddin A, et al. Global and Local Mutations in Bangladeshi SARS-CoV-2 Genomes. bioRxiv. 2020;:2020.08.25.267658.

16. Saha I, Ghosh N, Maity D, Sharma N, Sarkar JP, Mitra K. Genome-wide analysis of Indian SARS-CoV-2 genomes for the identification of genetic mutation and SNP. Infect Genet Evol. 2020;85:104457-104457.

17. Sardar R, Satish D, Birla S, Gupta D. Comparative analyses of SAR-CoV2 genomes from different geographical locations and other coronavirus family genomes reveals unique features potentially consequential to host-virus interaction and pathogenesis. bioRxiv. 2020;:2020.03.21.001586.

18. Raghav S, Ghosh A, Turuk J, Kumar S, Jha A, Madhulika S, et al. SARS-CoV2 genome analysis of Indian isolates and molecular modelling of $\mathrm{D} 614 \mathrm{G}$ mutated spike protein with TMPRSS2 depicted its enhanced interaction and virus infectivity. bioRxiv. 2020;:2020.07.23.217430.

19. Sah R, Rodriguez-Morales AJ, Jha R, Chu DKW, Gu H, Peiris M, et al. Complete Genome Sequence of a 2019 Novel Coronavirus (SARS-CoV-2) Strain Isolated in Nepal. Microbiol Resour Announc. 2020;9. 
20. Ghanchi NK, Masood KI, Nasir A, Khan W, Abidi SH, Shahid S, et al. SARS-CoV-2 genome analysis of strains in Pakistan reveals GH, S and L clade strains at the start of the pandemic. bioRxiv. $2020 ;: 2020.08 .04 .234153$.

21. Saif R, Mahmood T, Ejaz A, Zia S, Qureshi AR. Whole Genome Comparison of Pakistani Corona Virus with Chinese and US Strains along with its Predictive Severity of COVID-19. bioRxiv. $2020 ;: 2020.05 .01 .072942$.

22. DA S, PMSDK P, JMKJK P, LJAP J, GA P, SK Y. Evolutionary and genomic analysis of four SARSCoV-2 isolates circulating in March 2020 in Sri Lanka; Additional evidence on multiple introduction and further transmission. 2020.

23. MOPH-COVID-19 Dashboard. http://covid.moph-dw.org/\#/. Accessed 9 Oct 2020.

24. IEDCR. http://old.iedcr.gov.bd/. Accessed 9 Sep 2020.

25. Dashboard:: National Centre for Disease Control (NCDC). https://ncdc.gov.in/dashboard.php. Accessed 9 Oct 2020.

26. COVID-19 DASHBOARD - COVID-19. https://covid19.health.gov.mv/dashboard/?c=0. Accessed 9 Oct 2020 .

27. CoVid19-Dashboard. https://covid19.mohp.gov.np/. Accessed 9 Oct 2020.

28. Pakistan-Coronavirus Live Update. https://datastudio.google.com/reporting/4f8d15d3-751a-44ef-a5f7f5f171cb570d/page/yVNJB. Accessed 9 Sep 2020.

29. COVID-19 Dashboard Sri Lanka. http://covid19sl.com/?fbclid=IwAR0p28pI7xbOCR_GK8IL6hLzGc3NTqNdjMU2u5MTf5frCIvti8-v5sqxiu4. Accessed 9 Sep 2020.

30. Sharma G, Volgman AS, Michos ED. Sex Differences in Mortality From COVID-19 Pandemic. JACC Case Reports. 2020;2:1407-10. doi:10.1016/j.jaccas.2020.04.027.

31. Chen L, Li X, Chen M, Feng Y, Xiong C. The ACE2 expression in human heart indicates new potential mechanism of heart injury among patients infected with SARS-CoV-2. Cardiovasc Res. 2020;116:1097-100.

32. Bwire GM. Coronavirus: Why Men are More Vulnerable to Covid-19 Than Women? SN Compr Clin Med. 2020;:1.

33. Schurz H, Salie M, Tromp G, Hoal EG, Kinnear CJ, Möller M. The X chromosome and sex-specific effects in infectious disease susceptibility. Human genomics. 2019;13:2.

34. CDC. Excessive Alcohol Use and Risks to Women's Health. Centre for Disease Control Fact Sheets. 2014. http://www.cdc.gov/alcohol/fact-sheets/womens-health.htm. Accessed 5 Oct 2020.

35. Higgins ST, Kurti AN, Redner R, White TJ, Gaalema DE, Roberts ME, et al. A literature review on prevalence of gender differences and intersections with other vulnerabilities to tobacco use in the United States, 2004-2014. Preventive Medicine. 2015;80:89-100.

36. Coronavirus: A Look at Gender Differences in Awareness and Actions | KFF. https://www.kff.org/coronavirus-covid-19/issue-brief/coronavirus-a-look-at-gender-differences-inawareness-and-actions/. Accessed 5 Oct 2020.

37. Global Progress on COVID-19 Serology-Based Testing. https://www.centerforhealthsecurity.org/resources/COVID19/serology/Serology-based-tests-for-COVID-19.html. Accessed 11 Sep 2020.

38. Technical guidance publications. https://www.who.int/emergencies/diseases/novel-coronavirus2019/technical-guidance-publications. Accessed 13 Oct 2020.

39. Watson J, Whiting PF, Brush JE. Interpreting a covid-19 test result. The BMJ. 2020;369. 
40. Corman VM, Eckerle I, Bleicker T, Zaki A, Landt O, Eschbach-Bludau M, et al. Detection of a novel human coronavirus by real-time reverse-transcription polymerase chain reaction. Eurosurveillance. 2012;17:20285.

41. Lu X, Whitaker B, Sakthivel SKK, Kamili S, Rose LE, Lowe L, et al. Real-time reverse transcription-pcr assay panel for middle east respiratory syndrome coronavirus. J Clin Microbiol. 2014;52:67-75.

42. Corman VM, Landt O, Kaiser M, Molenkamp R, Meijer A, Chu DK, et al. Detection of 2019 novel coronavirus (2019-nCoV) by real-time RT-PCR. Eurosurveillance. 2020;25:2000045.

43. INDIAN COUNCIL OF MEDICAL RESEARCH. Total Operational Laboratories reporting to ICMR. 2020; June. https://www.icmr.gov.in/pdf/covid/labs/COVID_Testing_Labs_23112020.pdf.

44. Afghanistan: COVID-19 Multi-Sectoral Response Operational Situation Report, 12 November 2020 - Afghanistan | ReliefWeb. https://reliefweb.int/report/afghanistan/afghanistan-covid-19-multi-sectoralresponse-operational-situation-report-12-0. Accessed 24 Nov 2020.

45. Increased testing capacity, essential step in fighting COVID-19. https://www.who.int/bangladesh/news/detail/08-10-2020-increased-testing-capacity-essential-step-infighting-covid-19. Accessed 21 Oct 2020.

46. World Health Organization. COVID-19 Weekly Situation Report. World Heal Organ. 2020;43 October:18. https://www.who.int/docs/default-source/searo/whe/coronavirus19/sear-weekly-reports/weeklysituation-report-week-37.pdf?sfvrsn=ac89cd23_2.

47. MALDIVES RESPONSE TO COVID-19. 2020; September:19-22. https://www.who.int/docs/default-source/maldives/maldives-covid-19-sitrep-22sep20209165e0ce1f2a4520b083b2429ff71260.pdf?sfvrsn=3c4fa58e_2.

48. New testing lab in Maldives as COVID 19 cases cross 12 000-ANI - BW Businessworld. http://www.businessworld.in/article/New-testing-lab-in-Maldives-as-COVID-19-cases-cross-12-000/12-112020-342136/?fbclid=IwAR1ohJZF2qW3JkEHUU6-a3QTMwi4Ycn6ARizAYWYr-_aamZtT2JPneMRghc. Accessed 24 Nov 2020.

49. List of Laboratories for COVID19 (RT-PCR) testing in Nepal. https://publichealthupdate.com/polymerase-chain-reaction-pcr-test-for-covid-19-in-nepal/. Accessed 24 Nov 2020.

50. COVID - 19 Laboratory Capacity National Institute of Health, Islamabad. 2020;21:1-9. https://doi.org/10.1016/j.tmaid.2020.101607\%0Ahttps://doi.org/10.1016/j.ijsu.2020.02.034\%0Ahttps://onlinelibrary.wiley.com

51. designated PCR laboratories.pdf. https://hpb.health.gov.lk/media/pdf/pcr-testing-1.pdf.

52. (PDF) Onset, Transmission, Impact, and Management of COVID-19 Epidemic at Early Stage in SAARC Countries. https://www.researchgate.net/publication/343734542_Onset_Transmission_Impact_and_Management_of_COVID-19_Epidemic_at_Early_Stage_in_SAARC_Countries. Accessed 19 Oct 2020.

53. Foundation TI. National Guidelines on Clinical Management of COVID-19. 2008; November.

54. An alternative way to trace Covid-19 | The Daily Star. https://www.thedailystar.net/frontpage/news/alternativeway-trace-covid-19-1922637. Accessed 17 Oct 2020.

55. Bangladesh scientists create $\$ 3$ kit. Can it help detect COVID-19? | Bangladesh | Al Jazeera. https://www.aljazeera.com/news/2020/03/24/bangladesh-scientists-create-3-kit-can-it-help-detectcovid-19/?gb=true. Accessed 17 Oct 2020.

56. Kinley G, Adeep M, Jit Bdr D, Lila Maya A, Sonam W, Tandin D. A Descriptive Study of Confirmed COVID-19 Cases in Bhutan. J Infect Dis Epidemiol. 2020;6. 
57. MoH running 10,000 plus COVID-19 tests along Southern border, Thimphu and Paro to check for Community Transmission - The Bhutanese. https://thebhutanese.bt/moh-running-10000-plus-covid-19-tests-alongsouthern-border-thimphu-and-paro-to-check-for-community-transmission/. Accessed 18 Oct 2020.

58. Covid-19 Test Types, Process, Centres, Results, Price in India: What types of covid-19 tests are being carried out in India now? https://indianexpress.com/article/explained/coronavirus-covid-19testing-procedures-in-india-6479312/?fbclid=IwAR0wui0kXJMgg9DHPgHG3lY9XvCCnt92snE18oMB02_4e-qWprho05_uqe8. Accessed 18 Oct 2020.

59. What is the Feluda Paper Strip Test for Covid-19 Approved by India and How it Works Explained. https://www.news18.com/news/india/faq-what-is-the-feluda-paper-strip-covid-19-testapproved-by-india-and-how-it-works-explained-2895819.html. Accessed 18 Oct 2020.

60. COVID-19 | Encourage pvt. labs using TrueNat/CBNAAT tests to get NABL accreditation, ICMR tells States - The Hindu. https://www.thehindu.com/sci-tech/health/covid-19-encourage-pvt-labs-usingtruenatcbnaat-tests-to-get-nabl-accreditation-icmr-tells-states/article31986843.ece. Accessed 18 Oct 2020.

61. COVID-19 testing: Indigenous ELISA kits $92.37 \%$ sensitive and $97.9 \%$ specific, says ICMR | India News | Zee News. https://zeenews.india.com/india/covid-19-testing-indigenous-elisa-kits-92-37sensitive-and-97-9-specific-says-icmr-2288192.html?fbclid=IwAR3u_J62ab252a3J_3rq0nwOnjJL3WCwc_WL-RTJjE0ISiWV9VJ0TRFa65g. Accessed 18 Oct 2020.

62. WHO donates GeneXpert cartridges to Maldives - The Edition. https://edition.mv/news/17562. Accessed 19 Oct 2020.

63. Medtech brings rapid-result COVID-19 test kits to Maldives - The Edition. https://edition.mv/news/19427. Accessed 20 Oct 2020.

64. Medtech brings 18 ventilators to Maldives, gifts 1000 antibody tests - The Edition. https://edition.mv/news/16636. Accessed 20 Oct 2020.

65. Rapid test kits procured by Omni only accurate 50 percent of the time, says report. https://kathmandupost.com/health/2020/06/18/rapid-test-kits-procured-by-omni-only-accurate-50percent-of-the-time-says-report. Accessed 19 Oct 2020.

66. COVID-19: Digital, rapid tests to help Pakistan fight pandemic| Pakistan - Gulf News. https://gulfnews.com/world/asia/pakistan/covid-19-digital-rapid-tests-to-help-pakistan-fight-pandemic1.70869089. Accessed 18 Oct 2020.

67. carrying-out-test.pdf.

68. Covid-19: Over 1 million dead in 8 months | Dhaka Tribune. https://www.dhakatribune.com/health/coronavirus/2020/09/27/global-coronavirus-death-toll-surpasses-1million. Accessed 20 Oct 2020.

69. In Afghanistan, a Drug Sparks Hope - and Charges of Quackery. https://undark.org/2020/08/10/afghanistan-covid-19-drug-quackery/. Accessed 10 Oct 2020.

70. Afghan Gov't Warns Against Popular But Unproven Coronavirus Treatment. https://gandhara.rferl.org/a/afghan-gov-t-warns-against-popular-but-unproven-coronavirustreatment/30646578.html. Accessed 12 Oct 2020.

71. Covid-19: BMCH physician reports 'amazing results' using ivermectin, Doxycycline. https://www.unb.com.bd/category/Bangladesh/covid-19-bmch-physician-reports-amazing-results-usingivermectin-doxycycline/52634. Accessed 11 Oct 2020.

72. Beximco Pharma exports Covid-19 drug remdesivir | Dhaka Tribune. https://www.dhakatribune.com/bangladesh/2020/07/22/beximco-pharma-exports-covid-19-drugremdesivir. Accessed 11 Oct 2020. 
73. A Pandemic Review of COVID-19 Situation in Bangladesh. J Biosci Biomed Eng. 2020. doi:10.47485/2693-2504.1007.

74. Bangladesh recommends controversial drugs for Covid-19 treatment | The Business Standard. https://tbsnews.net/coronavirus-chronicle/covid-19-bangladesh/bangladesh-recommends-controversialdrugs-covid-19. Accessed 12 Oct 2020.

75. Use plasma therapy for Covid-19 patients with caution: Health experts. https://www.thefinancialexpress.com.bd/health/use-plasma-therapy-for-covid-19-patients-with-cautionhealth-experts-1592558065. Accessed 12 Oct 2020.

76. LeVine S, Dhakal GP, Penjor T, Chuki P, Namgyal K, Tshokey, et al. Case report: The first case of COVID-19 in Bhutan. Am J Trop Med Hyg. 2020;102:1205-7.

77. Tshokey T. An update on COVID-19 in Bhutan. Bhutan Heal J. 2020;6:III-III.

78. Sharma S, Basu S, Shetti NP, Aminabhavi TM. Current treatment protocol for COVID-19 in India. Sensors Int. 2020;1:100013.

79. Favipiravir and Remdesivir approved for Covid-19 treatment in India. https://www.nshealthcare.com/news/favipiravir-remdesivir-covid-19-india/. Accessed 12 Oct 2020.

80. Biocon's drug Itolizumab gets approval to treat Covid-19. https://www.pharmaceuticaltechnology.com/news/biocon-itolizumab-approval/. Accessed 12 Oct 2020.

81. Coronavirus India: Rush for plasma therapy as Covid-19 cases rise - BBC News. https://www.bbc.com/news/world-asia-india-53387607. Accessed 13 Oct 2020.

82. COVID-19 Quick Reference SOPs (Version 8).MINISTRY OF HEALTH - Downloads. http://health.gov.mv/Downloads?fbclid=IwAR0RYlfSezjndj586b4ogKpvpeWiy5621Tut6erTjOjwRsZor5xxvaHOsw. Accessed 12 Oct 2020.

83. IAF airlifts 6.2 tonne essential drugs to Maldives - The Hindu. $\quad$ https://www.thehindu.com/news/national/iaf-airlifts-62-tonne-essential-drugs-tomaldives/article31240436.ece. Accessed 12 Oct 2020.

84. All of Nepal's Covid-19 patients recovering with at least three to be discharged next week once they test negative. https://kathmandupost.com/health/2020/04/12/all-of-nepal-s-covid-19-patients-recoveringwith-at-least-three-to-be-discharged-next-week-once-they-test-negative. Accessed 12 Oct 2020.

85. Remdesivir now available in Nepal to treat COVID-19 patients. https://risingnepaldaily.com/mainnews/remdesivir-now-available-in-nepal-to-treat-covid-19-patients. Accessed 12 Oct 2020.

86. Covid-19: Nepal reports successful plasma therapy treatment | The Business Standard. https://tbsnews.net/coronavirus-chronicle/covid-19-nepal-reports-successful-plasma-therapy-treatment115201. Accessed 12 Oct 2020.

87. Pakistan mulls using dexamethasone on COVID-19 patients. https://www.aa.com.tr/en/asiapacific/pakistan-mulls-using-dexamethasone-on-covid-19-patients/1879967. Accessed 11 Oct 2020.

88. HCQ tablets proving effective in treatment of COVID-19 patients, claims top medicine expert. https://www.thenews.com.pk/print/667009-hcq-tablets-proving-effective-in-treatment-of-covid19-patients-claims-top-medicine-expert. Accessed 12 Oct 2020.

89. Punjab approves Covid-19 drug for trial use. https://www.thenews.com.pk/print/664802-punjabapproves-covid-19-drug-for-trial-use. Accessed 11 Oct 2020.

90. Anti-Covid drug to be available in three weeks - Pakistan - DAWN.COM. https://www.dawn.com/news/1567496. Accessed 13 Oct 2020. 
91. Coronavirus in Pakistan: Blood plasma in high demand to cure COVID-19 patients | Asia| An in-depth look at news from across the continent | DW | 01.07.2020. https://www.dw.com/en/coronavirus-pakistan/a54016553. Accessed 11 Oct 2020.

92. Topics hecent. http://www.epid.gov.lk/web/index.php?option=com_content\&view $=$ article\&id=131:topics-recent\&Itemid $=487 \&$ lang $=$ en. Accessed 12 Oct 2020 .

93. SRI LANKA Coronavirus: Ayurvedic prevention and treatment, but many break the curfew. http://www.asianews.it/news-en/Coronavirus:-Ayurvedic-prevention-and-treatment,-but-many-breakthe-curfew-49778.html. Accessed 12 Oct 2020.

94. Sri Lanka to introduce herbal medicine to fight COVID-19 | MENAFN.COM. https://menafn.com/1100929793/Sri-Lanka-to-introduce-herbal-medicine-to-fight-COVID-19. Accessed 12 Oct 2020.

95. COVID-19 Alert: Afghanistan Continues Imposing Restrictions Through Early September | WorldAware. https://www.worldaware.com/covid-19-alert-afghanistan-continues-imposing-restrictions-through-earlyseptember. Accessed 16 Oct 2020.

96. Policy Responses to COVID19. https://www.imf.org/en/Topics/imf-and-covid19/Policy-Responses-toCOVID-19. Accessed 15 Oct 2020.

97. Mitigating the poverty implications of COVID-19 in Afghanistan. https://blogs.worldbank.org/endpovertyinsouthasia/mitigating-poverty-implications-covid-19-afghanistan. Accessed 18 Oct 2020.

98. COVID-19 timeline in Bangladesh - Better Work. https://betterwork.org/portfolio/covid-timeline-inbangladesh/. Accessed 17 Oct 2020.

99. Govt to divide country into red, yellow, and green zones | The Business Standard. https://tbsnews.net/coronavirus-chronicle/covid-19-bangladesh/country-be-divided-red-green-and-yellowzones-87427. Accessed 16 Oct 2020.

100. GOVERNMENT MEASURES TO FIGHT COVID-19: Is it enough? https://www.newagebd.net/article/103791/government-measures-to-fight-covid-19-is-it-enough. Accessed 16 Oct 2020 .

101. Bangladesh's stimulus packages: Biggies look hungry, but minnows lose appetite. https://www.thefinancialexpress.com.bd/economy/bangladesh/bangladeshs-stimulus-packages-biggieslook-hungry-but-minnows-lose-appetite-1602560626. Accessed 18 Oct 2020.

102. COVID vaccine: Globe Biotech ready to start clinical trial. https://www.thefinancialexpress.com.bd/health/covid-vaccine-globe-biotech-ready-to-start-clinical-trial1599881476. Accessed 18 Oct 2020.

103. Bhutan's preparedness and response to COVID19 | ORF. https://www.orfonline.org/expertspeak/bhutans-preparedness-and-response-to-covid19-64711/. Accessed 18 Oct 2020.

104. Stay Home App | Ministry of Health. http://www.moh.gov.bt/stay-home-app-2/. Accessed 18 Oct 2020.

105. Druk Trace | Ministry of Health. http://www.moh.gov.bt/druk-trace/. Accessed 18 Oct 2020.

106. India observes Janata curfew, millions stay indoors, Health News, ET HealthWorld. https://health.economictimes.indiatimes.com/news/diagnostics/india-observes-janata-curfew-millionsstay-indoors/74757440. Accessed 18 Oct 2020.

107. India launches WhatsApp chatbot to create awareness about coronavirus, asks social media services to curb spread of misinformation | TechCrunch. https://techcrunch.com/2020/03/21/india-whatsapp-mygovcorona-helpdesk-bot/. Accessed 15 Oct 2020. 
108. Consumer Affairs dept partners with 2 startups to power 'Suraksha Store initiative' - The Hindu BusinessLine. https://www.thehindubusinessline.com/info-tech/consumer-affairs-dept-partners-with-2-startupsto-power-suraksha-store-initiative/article31556749.ece. Accessed 10 Oct 2020.

109. India's Covid-19 stimulus package - Maier+Vidorno. https://www.maiervidorno.com/indias-covid-19stimulus-package/. Accessed 18 Oct 2020.

110. COVID-19 vaccine update: DGCI panel gives nod to phase 3 trials of Bharat Biotech's Covaxin. https://www.dnaindia.com/india/report-covid-19-vaccine-update-dgci-panel-gives-nod-to-phase-3trials-of-bharat-biotech-s-covaxin-2851740. Accessed 18 Oct 2020.

111. Maldives reports first domestic case of coronavirus, total tally rises to 16- The New Indian Express. https://www.newindianexpress.com/world/2020/mar/28/maldives-reports-first-domestic-caseof-coronavirus-total-tally-rises-to-16-2122676.html. Accessed 18 Oct 2020.

112. MALDIVES RESPONSE TO COVID-19 -World Health Organization.Summary of the response till date Key Interventions. 2020; July.

113. Maldives government builds luxury coronavirus quarantine resort | London Evening Standard. https://www.standard.co.uk/lifestyle/travel/maldives-coronavirus-quarantine-resort-a4386856.html. Accessed 18 Oct 2020.

114. MALDIVES RESPONSE TO COVID-19. https://www.who.int/docs/defaultsource/maldives/maldives-covid-19-sitrep-22sep-20209165e0ce1f2a4520b083b2429ff71260.pdf?sfvrsn=3c4fa58e_2. Accessed 21 Oct 2020.

115. Nepal confirms first case of new coronavirus | Reuters. https://www.reuters.com/article/us-chinahealth-nepal-idUSKBN1ZN1S2. Accessed 18 Oct 2020.

116. PM Oli highlights Nepal's effort to combat COVID-19 in SAARC vid-con. https://risingnepaldaily.com/mustread/pm-oli-highlights-nepals-effort-to-combat-covid-19-in-saarc-vidcon. Accessed 18 Oct 2020.

117. Nepal UN. Preparedness and Response plan (nprp). 2020; April. https://www.who.int/docs/defaultsource/nepal-documents/novel-coronavirus/covid-19-nepal-preparedness-and-response-plan-(nprp)-draftapril-9.pdf?sfvrsn=808a970a_2.

118. Rana K, Bhandari S. COVID-19: preparedness, challenges, public health concern and government efforts in nepal. J Public Heal Policy Plan. 2020;4. doi:10.35841/public-health-policy.4.3.38-40.

119. The race to trial Covid-19 vaccines in Nepal - The Record. https://www.recordnepal.com/wire/features/the-race-to-trial-covid-19-vaccines-in-nepal/. Accessed 18 Oct 2020 .

120. 10 steps Pakistan is taking to contain coronavirus | Pakistan - Gulf News. https://gulfnews.com/world/asia/pakistan/10-steps-pakistan-is-taking-to-contain-coronavirus-1.70403640. Accessed 19 Oct 2020 .

121. 'Smart lockdown' in Pakistan to target 500 coronavirus hotspots | Pakistan | Al Jazeera. https://www.aljazeera.com/news/2020/6/23/smart-lockdown-in-pakistan-to-target-500-coronavirushotspots. Accessed 19 Oct 2020.

122. Largest fiscal stimulus package for Covid-19 relief given, says minister. https://nation.com.pk/17-Oct2020/largest-fiscal-stimulus-package-for-covid-19-relief-given-says-minister. Accessed 19 Oct 2020.

123. Phase 3 trials of Covid vaccine to begin in Karachi's Indus Hospital next week | The Express Tribune. https://tribune.com.pk/story/2264437/phase-3-trials-of-covid-vaccine-to-begin-in-karachis-indushospital-next-week. Accessed 19 Oct 2020. 
124. COVID-19 WEEKLY SITUATION REPORT. https://www.who.int/docs/defaultsource/searo/whe/coronavirus19/sear-weekly-reports/weekly-situation-report-week37.pdf?sfvrsn=ac89cd23_2. Accessed 21 Oct 2020.

125. Ministry of Health SL. Sri Lanka Preparedness \& Response Plan COVID19. Minist Heal Indig Med Serv. 2020; April. http://www.health.gov.lk/moh_final/english/public/elfinder/files/publications/2020/SPRP.pdf?fbclid=IwAR2w3xm82S_iy3rW-

1IC6EDdC7DnFB_JvA1oKaa_x_Nx_ckr75jdsT6hc9E.

126. Koyama T, Platt D, Parida L. Variant analysis of SARS-cov-2 genomes. Bull World Health Organ. 2020;98:495-504.

127. Omori R, Matsuyama R, Nakata Y. The age distribution of mortality from novel coronavirus disease (COVID-19) suggests no large difference of susceptibility by age. Sci Rep. 2020;10. 